of the 3154 deliveries in one Liverpool hospital in 1986 were to teenage girls. Only $14 \%$ breast fed their infants.

Many pupils regarded bottle feeding as more convenient and fashionable. Cost was unimportant. Some girls thought that formular feeds were free as milk tokens were available for all. One boy argued that bottle feeding was safer, as the baby could not catch AIDS.

The most positive influence on the pupils' choice of feeding was previous experience of breast feeding; this has been shown in other studies. ${ }^{+5}$ What are the implications for change where few have the opportunity to see a baby breast fed? Infant feeding should be a topic in health education for both sexes from the earliest school years. This study suggests that by the fourth form embarrassment is firmly fixed. More open discussion on breast feeding and its merits might reduce embarrassment and modify society's acceptance of the breast as a purely sexual organ. Most of our schoolchildren will become parents. School should be preparing them for parenthood as well as a career.

I thank Dr M Pearson, lecturer in medical sociology, university department of general practice, for advice in preparing the questionnaire and Dr E Poskitt for constructive criticism. Special thanks go to the staff and pupils who took part.

1 Martin J, White A. Infant fieding 1985. London: Office of Population Censuses and Surveys, 1988.

Eastham E, Smith D, Poole D, Neligan G. Further decline of breast feeding. $\mathrm{Br}$ Med f 1976;i:305-7.

3 Ellis DJ. Secondary school students' attitudes and beliefs about breast feeding. f Sch Health 1983;53:600-4.

4 Pascoe JM, Berger A. Attitudes of high school girls in Israel and the United States toward breast feeding. I Adolesc Health Care 1985;6:28-30.

5 Jones DA. The choice to breast feed or bottle feed and influences upon that choice: a survey of 1525 mothers. Child Care Health Dev 1987;13:75-85.

(Accepted 18 April 1989)

\title{
Risks of AIDS among workers in the "sex industry": some initial results from a Scottish study
}

\author{
Ruth Morgan Thomas, Martin A Plant, Moira L Plant, David I Sales
}

Alcohol Research Group, Department of Psychiatry, University of Edinburgh, Morningside Park, Edinburgh EH10 5HF Ruth Morgan Thomas, BA, research associate Martin A Plant, PHD, director Moira L Plant, PHD, research fellow

AFRC Institute of Animal Physiology and Genetics Research, Edinburgh David I Sales, MSC, principal scientific officer

Correspondence to: $\mathrm{Ms}$ Morgan Thomas.

BrMed f 1989;299:148-9
Abstract

Objective-To determine the extent to which workers in the "sex industry" in Edinburgh engage in activities with a high risk of infection with HIV.

Design-Cross sectional, single phase survey in which respondents were located by a non-random method ("snowballing").

Setting-Research project coordinated by the Alcohol Research Group, Edinburgh.

Subjects - 205 Sex workers (102 male, 103 female) interviewed between July and December 1988.

End point-Strategies to reduce risk of AIDS among people who buy and sell sexual services.

Measurements and main results-Data were elicited by a standardised interview which related to over 300 variables. A fifth of the study group had used drugs intravenously, and one in 12 reported that they had been found to be seropositive on HIV testing. Roughly a quarter of the study group sometimes engaged in unprotected sex with clients for more money, and a similar proportion sometimes did not seek medical advice even if they had genital or anal symptoms.

Conclusions-People who buy and sell sexual services should be priority targets for health education and strategies to reduce their risk of AIDS.

\section{Introduction}

The connection between commercial sex and sexually transmitted diseases has been extensively studied. ${ }^{\prime}$ During recent years concern about this link has been heightened by the AIDS epidemic. The connection between the "sex industry" and AIDS has been further accentuated by the fact that some of those who buy and sell sexual services are heavy users of alcohol or illicit drugs. ${ }^{2+4}$

In order to examine the behavioural aspects of risks of AIDS in relation to the sex industry a research project was initiated in Edinburgh. Edinburgh city has a population of around 500000 and a high rate of HIV infection. ${ }^{56}$ At the end of March 1989, 969 people had been recorded as HIV positive by Edinburgh hospitals. Over half of these $(533 ; 55 \%)$ were intravenous drug users, some of whom were known to provide commercial sex at least occasionally (personal communications 1988(V Morrison), 1988 (J R Robertson), 1989 (D Goldberg)). Several people have reportedly been infected as a result of sexual contact with Scottish drug users.'

This investigation was designed to achieve three main aims: (a) to examine the extent to which sex workers engage in activities with a high risk of HIV infection; $(b)$ to examine levels of alcohol and drug use among sex workers; and $(c)$ to determine patterns of AIDS related beliefs, knowledge, and attitudes among sex workers. This paper is concerned with the first aim.

\section{Subjects and methods}

For this study a "sex worker" is defined as someone who provides sexual services for money. Data were elicited by a standardised interview schedule containing questions on 333 variables. It was not possible to conduct a random survey, and respondents were therefore contacted by "snowballing." interviewers approaching subjects whom they knew to be sex workers and who in turn introduced them to others. This paper relates to the first 205 sex workers who were interviewed between July and December 1988.

\section{Results}

Of the 205 sex workers, 102 were male and 103 female. Their age range was 15 to 44 . Because of nonresponse to some items in the interview the totals presented below vary slightly. Initial fieldwork concentrated on people who mainly worked the streets and from hotels, discos, and bars. This is reflected by their usual methods of meeting clients, listed in table I.

Use of condoms - The sexes did not differ significantly in relation to their self reported use of condoms with clients (table II). Most respondents reported that they always or usually used condoms for penetrative sex with clients. Even so, a minority reported that they rarely or never used condoms. Respondents were asked whether they refused to use condoms for 
penetrative sex with clients. Six male and four female sex workers reported that they did. In addition, 25 males and 29 females reported that they sometimes charged clients more for unprotected sex. Male sex workers were more likely than female sex workers to report having condom failure during the past month $(30 / 88 v 18 / 83)$. Among respondents who had a current lover most (26/35 males, $31 / 54$ females) reported that they rarely or never used condoms when engaging in penetrative sex with that person.

TABLE I-Normal methods of meeting clients

\begin{tabular}{lccc}
\hline & $\begin{array}{c}\text { Male } \\
\text { sex workers }\end{array}$ & $\begin{array}{c}\text { Female } \\
\text { sex workers }\end{array}$ & Total \\
\hline Bar or hotel & 57 & 54 & 111 \\
Disco & 71 & 39 & 110 \\
Street & 35 & 43 & 78 \\
Other clients & 36 & 37 & 73 \\
Sex workers or pimps & 24 & 41 & 65 \\
Massage parlour/sauna & 3 & 29 & 32 \\
Escort agency & 1 & 19 & 20 \\
Advertising & 3 & 12 & 15 \\
Brothel & 3 & 5 & 8 \\
Club or host/hostess work & 0 & 1 & 1 \\
Other methods & 19 & 10 & 29 \\
& & &
\end{tabular}

Some respondents reported several ways of meeting clients.

TABLE II $-U$ se of condoms for intercourse with clients

\begin{tabular}{lcccccc}
\hline & \multicolumn{2}{c}{ Male sex workers } & & \multicolumn{2}{c}{ Female sex workers } \\
\cline { 2 - 3 } \cline { 6 - 7 } Frequency & No & $\%$ & & No & $\%$ \\
\hline Always & 63 & $73 \cdot 3$ & & 62 & $62 \cdot 6$ \\
Usually & 11 & $12 \cdot 8$ & & 14 & $14 \cdot 1$ \\
Sometimes & 7 & $8 \cdot 1$ & & 15 & $15 \cdot 2$ \\
Rarely & 5 & $5 \cdot 8$ & & 6 & $6 \cdot 1$ \\
Never & 86 & $100 \cdot 0$ & & 99 & $100 \cdot 0$ \\
Total & & &
\end{tabular}

Intravenous drug use-Forty one respondents (20\%) reported having used drugs intravenously. Female respondents were more likely than male respondents to report such drug use (28/101 $v$ 13/100). Female respondents were also more likely than male respondents to report that they currently used drugs intravenously $(18 / 101 v 6 / 100)$. Thirty nine subjects (19\%) reported having shared injecting equipment since 1980 .

HIV state-Respondents were asked whether they had been tested for HIV antibody and if so what the result of the last test had been. One hundred and twenty respondents $(58.5 \%)$ reported having been tested, of whom $17(8.3 \%$ of the study group) stated that the result had been positive. Nine other people refused to disclose their results. Of the $17 \mathrm{HIV}$ positive subjects, five were male. Fourteen of the 17 had used drugs intravenously. All three who claimed not to have injected drugs were female and presumably had become infected during unprotected sex.

Clinic attendance - Respondents were asked whether they attended a genitourinary medicine clinic or other medical practitioners for check ups. Only 109 respondents reported that they did so. In addition, 53 respondents stated that they sometimes refrained from having medical checks even when they had genital or anal symptoms.

Massage parlours, saunas, and escort agencies-Only 14 subjects, all female, currently worked solely in massage parlours or saunas or for escort agencies. Some other respondents had either done so previously or sometimes worked from these agencies. Only one of the 14 reported having ever injected drugs. Twelve of the 14 reported having been tested for HIV antibody, of whom 11 stated that their results had been negative and one declined to comment. Respondents who worked in massage parlours and saunas or for escort agencies were in many ways quite different from those who worked the streets or from hotels, discos, and other venues.

\section{Discussion}

These results were derived from self reports, and such data are inevitably flawed by denial and other limitations. ${ }^{10-12}$ Public health is not enhanced by attempts to curb prostitution, as historically these measures have been counterproductive by driving activities further underground.'

Sex workers and their clients are important targets for AIDS prevention. Health education must be accompanied by policies to encourage and eroticise the use of condoms. Action is needed to increase supplies and use of strengthened condoms for anal sex and acceptable condoms for oral sex. Some respondents indicated that for several reasons they were inhibited from buying adequate supplies of condoms or from having regular medical check ups. This poses a challenge for the health and social services. The social services should seek to emulate their counterparts in Amsterdam, where sex industry workers are encouraged to have regular medical checks (J Visser, P Uniken-Venema, personal communication, 1989). This policy has already been adopted in at least one London clinic. ${ }^{13}$

There is very little evidence that HIV infection in Britain has been spread by prostitution. Nevertheless, these results suggest that there is potentially a risk. Policies to minimise harm should be conducted at local level and ideally should be assessed. The brisk implementation of such policies will cost money but is likely to save far greater expenditure in future.

This study is being funded by the Medical Research Council. Additional support has been provided by the Scottish Health Education Group, the Scotch Whisky Association, and an anonymous charitable trust. We thank Ms Angelica Warner for helping to launch the fieldwork and Mrs Val Mannings and Mrs Janis Nichol for processing the text.

1 Darrow WW. Prostitution and sexually transmitted diseases. In: Holmes KK, Mardh P-A, Sparling PF, Wiesner PJ, eds. Sexually transmitted diseases. New York: McGraw Hill, 1984:109-15.

2 Goldstein PJ.Prostitution and drugs. Lexington, Mass: Lexington Books, 1979. 3 Weisberg DK. Children of the night. Lexington, Mass: Lexington Books, 1985. 4 Plant ML, Plant MA, Peck DF, Setters J. The sex industry, alcohol and illicit drugs: implications for the spread of HIV infection. Br $\mathcal{J}$ Addict 1989;84 53-9.

5 Robertson JR, Bucknall ABV, Welsby PD, et al. Epidemic of AIDS related virus (HTLV-III/LAV) infection among intravenous drug abusers. BrMed f 1986;292:527-9.

6 Robertson JR. Heroin, AIDS and society. London: Hodder and Stoughton, 1987.

7 Delamothe T. Scotrish AIDS. Br Med f 1989;298:141-2.

8 Plant MA. Drugtakers in an English town. London: Tavistock, 1975.

9 Morrison V. Observations and snowballing: useful tools for research into illicit drug use? Social Pharmacology 1988;2:245-71.

10 Plant MA, Peck DF, Samuel E. Alcohol, drugs and school leavers. London: Tavistock, 1986.

11 Singh A. Reliability and validity of self-reported delinquency studies: a review. Psychol Rep 1979;44:987-93.

12 Plant MA, Peck DF, Stuart R. The correlates of serious alcohol-related consequences and illicit drugs use amongst a cohort of Scottish teenagers. Br $\mathcal{F}$ Addict 1984;79:197-200.

13 Day S, Ward H, Harrison JRW. Prostitute women and public health. Br Med $\mathcal{J}$ 1988;297:1985.

(Accepted 31 May 1989) 